\title{
Examination of practical utility of remotely controlled robots in disasters
}

\author{
NAOKI Kimura \\ Kyusyu Regional Development Kyusyu Technical Office \\ Ministry of Land Infrastructure and Transport \\ 1-3-1 Takano Kurume City Fukuoka Pref. Japan \\ kimura-n8910@qsr.mlit.go.jp \\ AKIRA Fujioka \\ Civil Engineering Division \\ Fujita Corporation \\ 4-25-2 Sendagaya Shibuya Ward Tokyo Japan \\ fujioka@fujita.co.jp
}

\author{
SUNAO Inoue \\ Kyusyu Regional Development Kyusyu Technical Office \\ Ministry of Land Infrastructure and Transport \\ 1-3-1 Takano Kurume City Fukuoka Pref. Japan \\ inoue-s8910@qsr.mlit.go.jp \\ KATSUHIKO Kawakami \\ Civil Engineering Division \\ Fujita Corporation \\ 4-25-2 Sendagaya Shibuya Ward Tokyo Japan \\ kakawakami@fujita.co.jp
}

\section{Abstract}

The Technical Office of Kyushu (in the Kyushu Regional Development Bureau, Ministry of Land, Infrastructure and Transport) and Fujita Corporation have jointly developed a remotely controlled robot that can be rapidly installed in conventional commercially-available construction vehicles such as backhoes, bulldozers and crawler dump trucks.

This paper examines the practical utility (operability and performance) of the portable robot system when mounted in a backhoe and crawler dump truck. Testing was undertaken at a site where accumulated volcanic ash (caused by the eruption of Mt. Sakurajima, Kagoshima Prefecture, and subsequent mudslides) was being removed from around the Kurokami River. This report also examines long-distance operation of the remotely controlled robot using a wireless local area network (WLAN) with the aim of increasing the operational area of the robot-controlled vehicles.

Keywords: Remote Control, Robot, Wireless Local Area Network, Disaster

\section{Introduction}

In 1996, the Technical Office of Kyushu (part of the Kyushu Regional Development Bureau, Ministry of Land, Infrastructure and Transport) and Fujita Corporation jointly developed a remotely controlled portable robot that could be installed in commercially-available construction vehicles[1]. Since then, eight portable robots have been deployed in local disaster-prevention centers administered by the Kyushu Regional Development Bureau (six in backhoes, one in a bulldozer and one in a crawler dump truck).

The performance of a portable robot (mounted in a backhoe and a crawler dump truck) was examined at the Kurokami River in Sakurajima Island (shown in Photo-1). This paper assesses performance of the system for tasks such as excavation, loading and transportation of earth.

\section{Outline of the remotely controlled robot}

Once disasters such as landslides occur, emergency response should be rapid in order to minimize loss of human life and prevent secondary disasters. To ensure safety of emergency workers, construction vehicles used to remove the collapsed soil and rock should be remotely operated purpose-built, remote control construction vehicles have previously been used in this type of work.

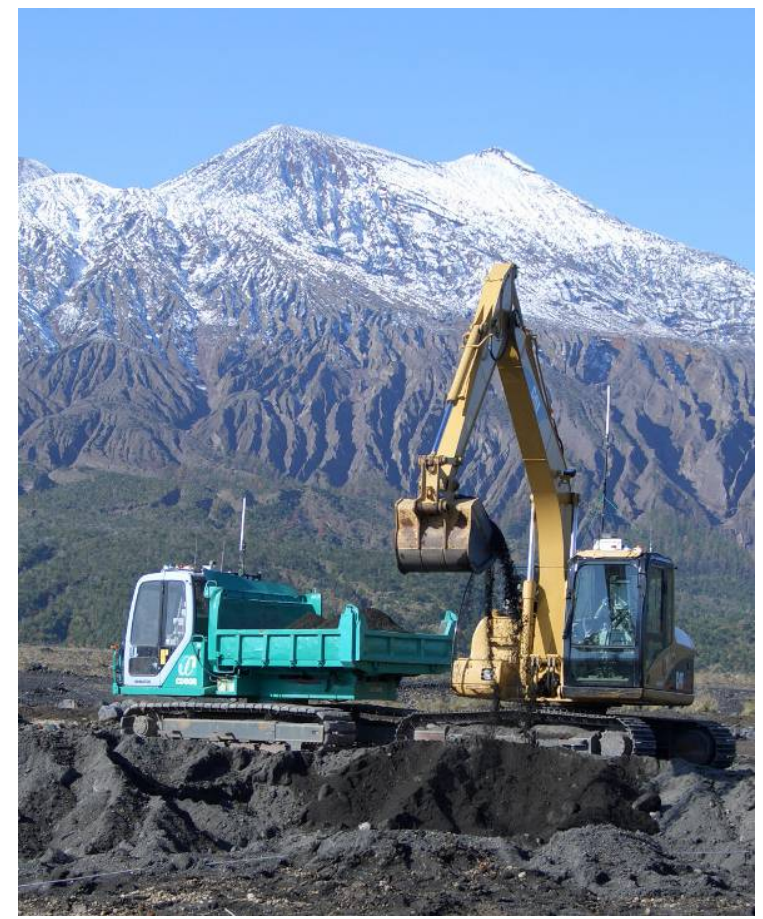

Photo-1 The performance of a portable robot (mounted in a backhoe and a crawler dump truck) at the Kurokami River in Sakurajima Island 


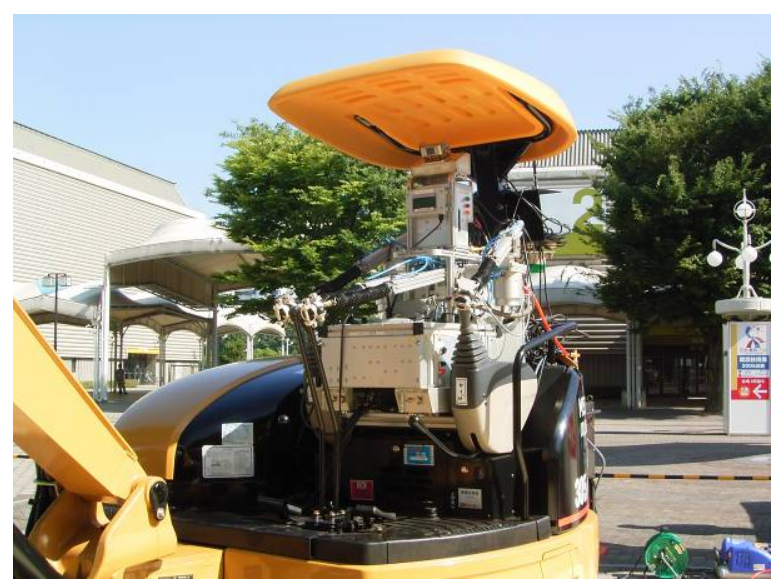

Photo-2 Remotely controlled robot mounted on backhoe

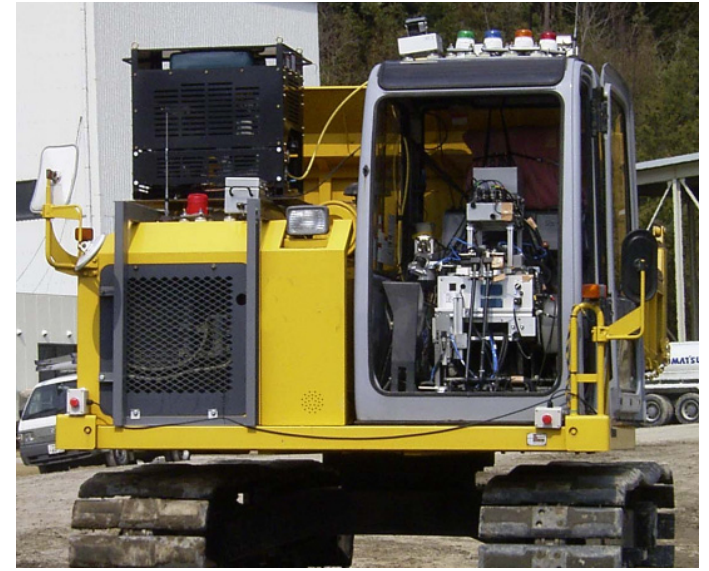

Photo-3 Remotely controlled robot mounted on crawler dump truck

Table-1 Specification of each robot

\begin{tabular}{|c|c|c|c|}
\hline Item & For backhoe & For crawler dump & For bulldozer \\
\hline Installation time & \multicolumn{3}{|c|}{ About three hours (Adjustments require a $2 \sim 3$ person crew) } \\
\hline Number of units & \multicolumn{3}{|l|}{10 pieces } \\
\hline Total weight & About $180 \mathrm{~kg}$ & About $150 \mathrm{~kg}$ & About 230kg \\
\hline Externals size(millimeter) & $\begin{array}{l}\text { Width }=620 \\
\text { Depth }=1,100 \\
\text { Height }=1,040\end{array}$ & $\begin{array}{l}\text { Width }=600 \\
\text { Depth }=920 \\
\text { Height }=800\end{array}$ & $\begin{array}{l}\text { Width }=1,000 \\
\text { Depth }=1,600 \\
\text { Height }=1,100\end{array}$ \\
\hline Wireless method & \multicolumn{3}{|c|}{ Control : Specified low power radio、Image : SS wireless } \\
\hline Remote-controlled distance & \multicolumn{3}{|c|}{ Within 150 300meter } \\
\hline Power supply & \multicolumn{3}{|c|}{ More than DC24V(Voltage of construction machinery battery) } \\
\hline Power consumption & \multicolumn{3}{|l|}{ Maximum 20W } \\
\hline Maximum use pressure & \multicolumn{3}{|c|}{$0.7 \mathrm{MPa}(7 \mathrm{kilogram} /$ pressure $)$} \\
\hline Amount of the maximum air use & \multicolumn{3}{|c|}{120 liter /minute(atmospheric pressure conversion) } \\
\hline
\end{tabular}

However, their low numbers, combined with the time and costs involved in their transportation, have prevented their widespread use. In order to overcome these problems, we developed a remotely controlled robot that can be easily and rapidly mounted on commercially-available construction vehicles, such as backhoes (shown in Photo-2), bulldozers and crawler dump trucks (shown in Photo-3). Table-1 shows the specification of robots for each vehicle.

\section{The purposes of the tests}

One of the aims of this paper is to examine the performance of the portable robot for common tasks such as excavation, loading and transporting when mounted on a backhoe and crawler dump truck. Another aim is to examine

the performance of long-distance operation using a wireless local area network (WLAN).

\section{Examination tests at Sakurajima Island}

\subsection{Outline of the tests}

Portable robots were mounted on a backhoe (capacity of $0.45 \mathrm{~m}^{3}$ ) and a crawler dump truck (capacity of 6 ton), and the vehicles simultaneously carried out excavation/loading (shown in Photo-4) and transportation (Photo-5) whilst under remote control. Photo-6 shows the remote control operation room. Figure-1 shows the overall view of the tests, and Figure- 2 shows a schematic of the wireless local area networks. To examine the effectiveness of the proposed system, four test cases were carried out as shown in Table-2.

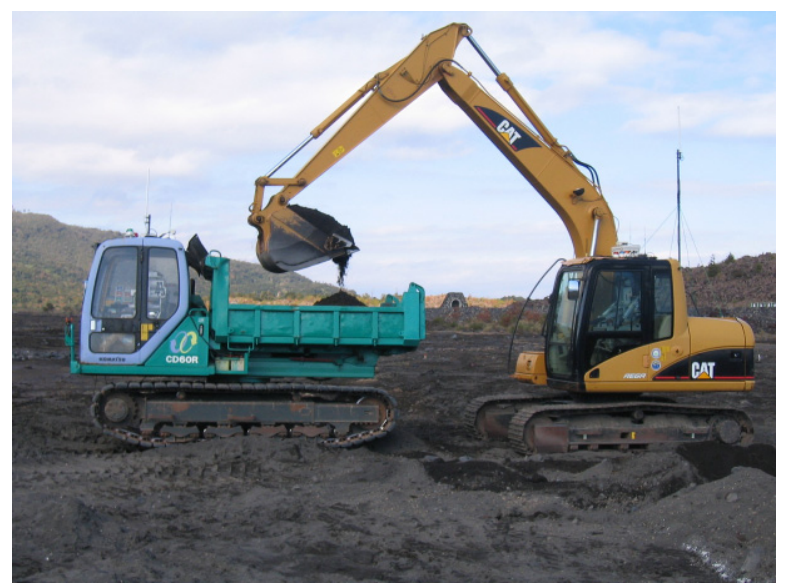

Photo-4 Excavation /loading 


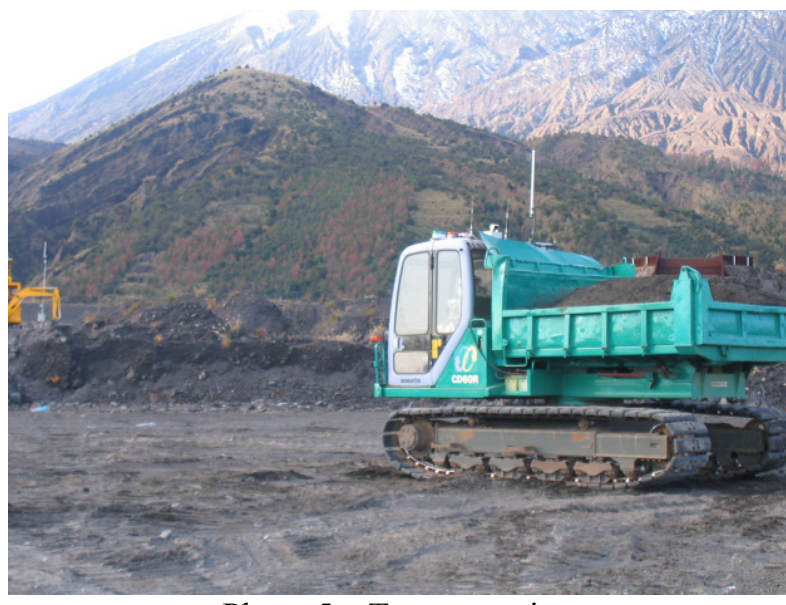

Photo-5 Transportation

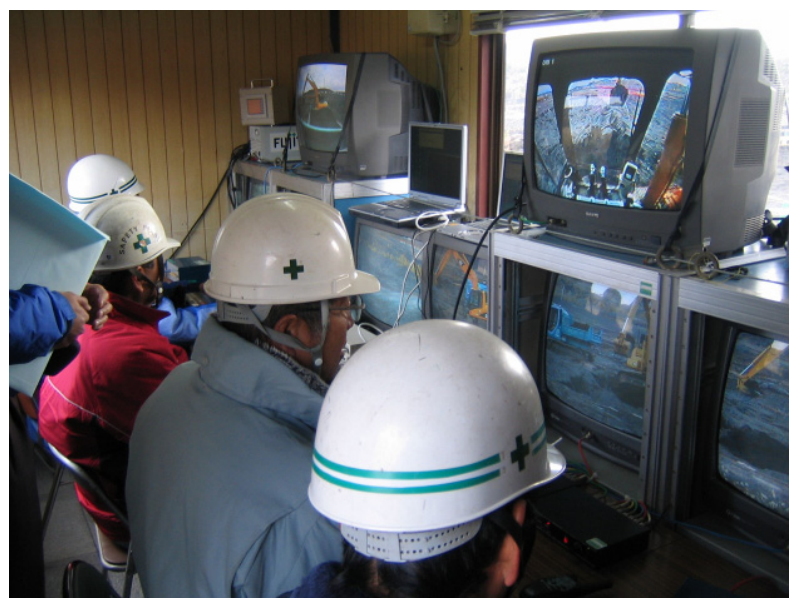

Photo-6 Remote control at operation room

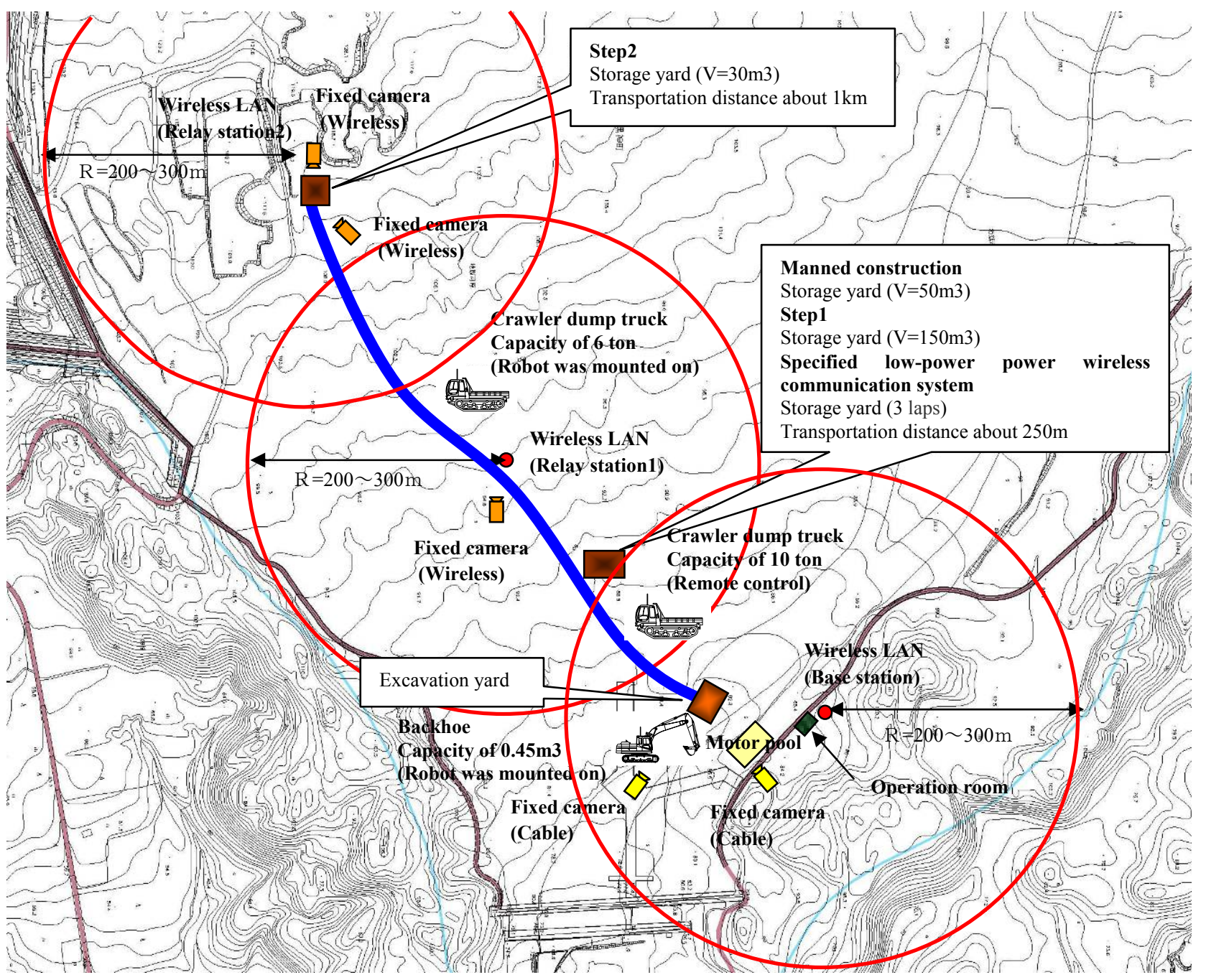

Figure-1 Overall view of unmanned construction system 


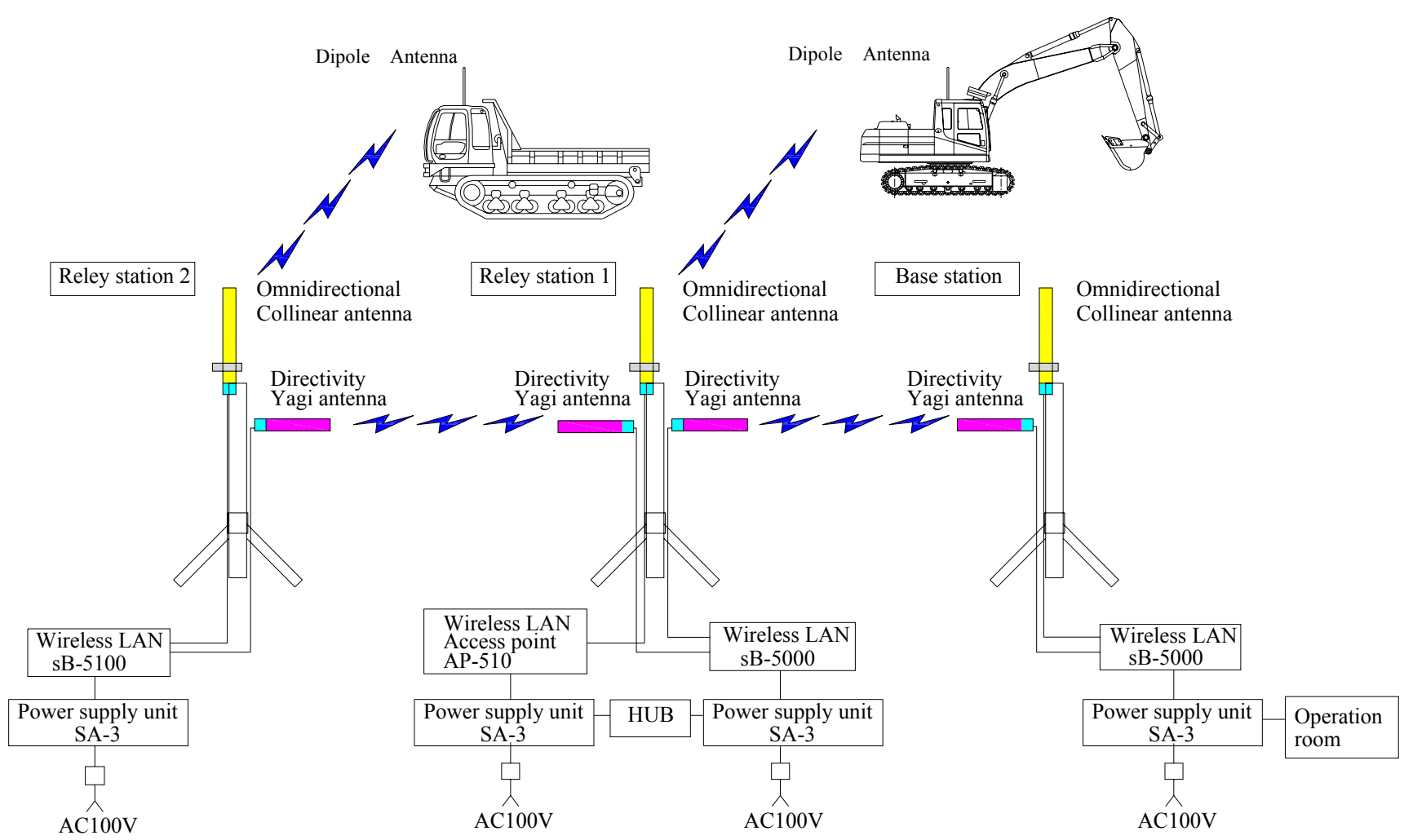

Figure-2 Composition chart of wireless LAN

Table-2 Details of the performance tests

\begin{tabular}{|c|c|c|c|c|}
\hline $\begin{array}{c}\text { Examination } \\
\text { item }\end{array}$ & $\begin{array}{c}\text { excavation } \\
\text { volume } \\
\text { transportation } \\
\text { distance }\end{array}$ & Use machine & Use wireless & Remarks \\
\hline $\begin{array}{l}\text { Case } 1 \\
\text { (Manned } \\
\text { construction) }\end{array}$ & $\begin{array}{l}50 \mathrm{~m}^{3} \\
250 \mathrm{~m}\end{array}$ & $\begin{array}{l}\text { (1) Backhoe } \\
0.45 \mathrm{~m}^{3} \text { (one) } \\
\text { (2) Crawler dump truck } 6 \mathrm{t} \text { (one) } \\
\text { (3) Crawler dump truck 10t (one) }\end{array}$ & $\begin{array}{l}\text { (Control) None } \\
\text { ( Image)None }\end{array}$ & \\
\hline $\begin{array}{l}\text { Case } 2 \\
(\text { STEP-1) }\end{array}$ & $\begin{array}{l}150 \mathrm{~m}^{3} \\
250 \mathrm{~m}\end{array}$ & $\begin{array}{l}\text { (1)Backhoe } 0.45 \mathrm{~m}^{3} \text { (one) } \\
\text { (2)Crawler dump truck 6t (one) } \\
\text { (3) Crawler dump truck 10t (one) } \\
\text { (Remote-controlled exclusive } \\
\text { use) } \\
\text { (4)Fixed camera (Cable) (two) }\end{array}$ & $\begin{array}{l}\text { (Control) wireless LAN } \\
\text { ( Image)wireless LAN } \\
\text { (Control) wireless LAN } \\
\text { ( Image)wireless LAN } \\
\text { (Control)specified low-power } \\
\quad \text { wireless } \\
\text { ( Image)None }\end{array}$ & $\begin{array}{l}\text { Robot and camera are } \\
\text { mounted in the backhoe } \\
\text { and the crawler dump } \\
\text { truck }\end{array}$ \\
\hline $\begin{array}{l}\text { Case } 3 \\
(\text { STEP-2) }\end{array}$ & $\begin{array}{l}30 \mathrm{~m}^{3} \\
1 \mathrm{~km}\end{array}$ & $\begin{array}{l}\text { (1)Backhoe } 0.45 \mathrm{~m}^{3} \text { (one) } \\
\text { (2) Crawler dump truck } 6 \mathrm{t} \text { (one) } \\
\text { (3) Fixed camera (Cable) (two) } \\
\text { (4)Fixed camera (wireless) (three) }\end{array}$ & $\begin{array}{l}\text { (Control) wireless LAN } \\
\text { ( Image)wireless LAN } \\
\text { (Control) wireless LAN } \\
\text { ( Image)wireless LAN }\end{array}$ & $\begin{array}{l}\text { Robot and camera are } \\
\text { mounted in the backhoe } \\
\text { and the crawler dump } \\
\text { truck }\end{array}$ \\
\hline $\begin{array}{l}\text { Case } 4 \\
\text { (specified } \\
\text { low-power } \\
\text { wireless) }\end{array}$ & $\begin{array}{l}9 \mathrm{~m}^{3} \\
250 \mathrm{~m}\end{array}$ & $\begin{array}{l}\text { (1)Backhoe } 0.45 \mathrm{~m}^{3} \text { (one) } \\
\text { (2)Crawler dump truck } 6 \mathrm{t} \text { (one) } \\
\text { (3)Fixed camera (Cable) (two) }\end{array}$ & $\begin{array}{l}\text { (Control)specified low-power } \\
\text { wireless } \\
\text { ( Image)wireless LAN } \\
\text { (Control)specified low-power } \\
\quad \text { wireless } \\
\text { ( Image)wireless LAN }\end{array}$ & $\begin{array}{l}\text { Robot and camera are } \\
\text { mounted in the backhoe } \\
\text { and the crawler dump } \\
\text { truck }\end{array}$ \\
\hline
\end{tabular}


4.2 Results of the tests

4.2.1 Performance of the backhoe controlled by the portable robot

The performance of the backhoe (measured as excavation volume per hour) is shown in Figure-3. The following results were obtained;

(1) There was no measurable difference in performance between use of a wireless local area network (WLAN) system and the specified low-power wireless communication system.

(2) It is well documented that the excavation performance of a purpose-built remotely operated backhoe using the specified low-power wireless communication system is $60 \%$ of that of a manned operated backhoe[2]. From Figure-3, it is clear that the performance of the portable robot attached to a backhoe achieves this standard, whether under control from a WLAN-based or a specified low-power wireless communication system.

\subsubsection{Performance of the crawler dump truck controlled by} the portable robot

The performance of the portable robot-controlled crawler dump truck (shown in Figure-4) was estimated based on the cycle time and transportation soil volume in series of procedures (transportation with loading, unloading and transportation without loading). The performance of the crawler dump truck is shown in Figure-4. The following results were obtained.

(1) From the "STEP-1" test, the transportation efficiency of a crawler dump truck with the portable robot is around $60 \%$ of that of manned crawler dump truck (including degradation in performance as the vehicle switched between different WLAN base stations). Without this degradation caused by roaming between base stations, the efficiency of the portable robot-controlled crawler dump truck may be greater than $70 \%$ that of a manned crawler dump truck (and almost same as for a specially built, remotely controlled crawler dump truck).

(2) In the case of the "STEP-2" test, it is relatively difficult to compare performance, as the transportation distance of "STEP-2" was longer than that of other cases. As the transportation distance increases, so the performance of the robot-controlled crawler dump truck tends to approach that of the manned crawler dump truck. In this final test, the allowed velocity of the crawler dump truck was higher than other cases. If this higher velocity had been used in the other tests, performance is likely to have increased.

(3) The performance of crawler dump truck with the portable robot was $90 \%$ of that of manned crawler dump truck. The efficiency of transportation was higher than that of excavation works because the procedure is usually simpler. However, as the test excavation soil volume was only $9 \mathrm{~m}^{2}$, tests with higher soil excavation volumes should be carried out to compare the efficiency more accurately.

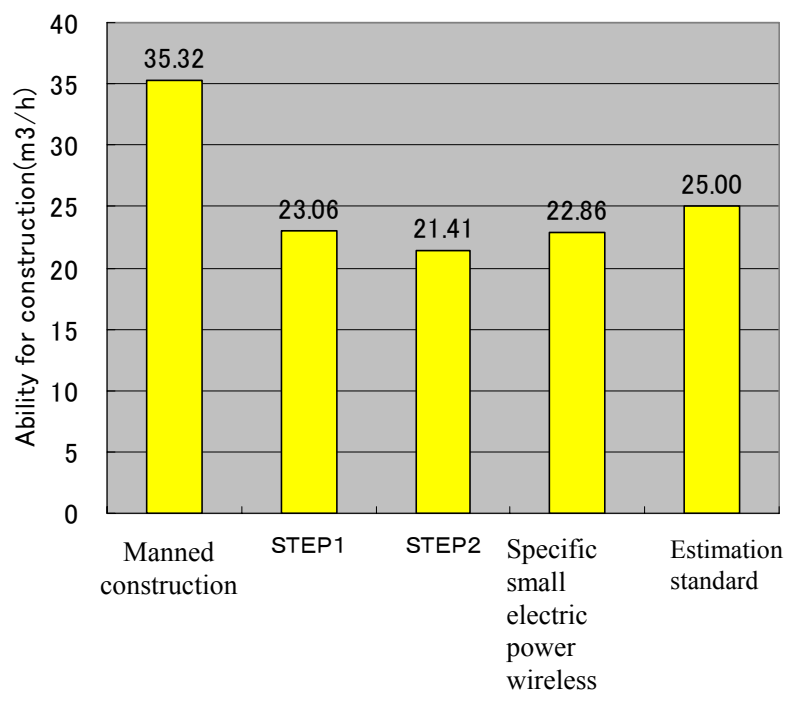

Figure -3 Performance of backhoe

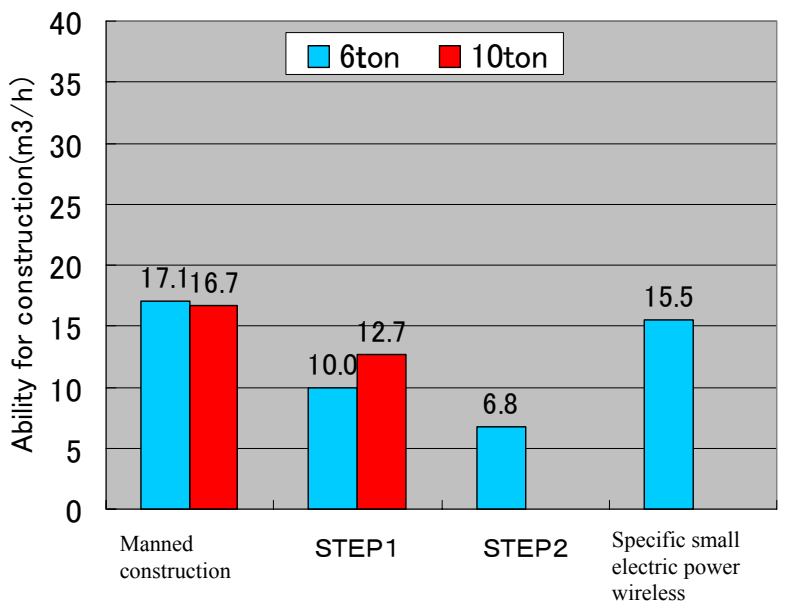

Figure -4 Performance of the crawler dump truck

4.2.3 Examination test results for wireless local area network

In the "STEP-2" test, the applicability of wireless local area network communication system to the remotely-operated robot system was examined. The test was carried out by changing following parameters; 1) locations of base station and relay stations (1 and 2), 2) types and directions of antennas, 3) radio transmission power. The most effective combination of parameters is shown in Table-3. In the test, the communication system was sometimes stopped due to the effect of roaming of crawler dump truck, and the major causes are detailed in Table-4. 
Table-3 The type of antenna and radio transmission power

\begin{tabular}{|c|c|c|}
\hline Station & type of antenna & radio transmission power \\
\hline Base station & Plane Antenna & strong \\
\hline Relay station1 & None & weak \\
\hline Relay station2 & Dipole Antenna & . \\
\hline
\end{tabular}

Table -4 Position where crawler dump truck is stopped and the cause

\begin{tabular}{|c|c|c|c|c|}
\hline \multirow{2}{*}{$\begin{array}{l}\text { Roaming } \\
\text { malfunction }\end{array}$} & \multicolumn{2}{|c|}{ Way } & \multicolumn{2}{|c|}{ Return } \\
\hline & point $250 \mathrm{~m}$ & point $470 \mathrm{~m}$ & point $450 \sim 550 \mathrm{~m}$ & point $700 \mathrm{~m}$ \\
\hline Antenna & $\begin{array}{l}\text { base station } \\
\text { (Plane Antenna) }\end{array}$ & $\begin{array}{l}\text { relay station2 } \\
\text { (Dipole Antenna) }\end{array}$ & $\begin{array}{l}\text { relay station2 } \\
\text { (Dipole Antenna) }\end{array}$ & $\begin{array}{l}\text { relay station2 } \\
\text { (Dipole Antenna) }\end{array}$ \\
\hline Cause & $\begin{array}{l}\text { The directions of plane } \\
\text { antenna and the } \\
\text { inclination of antenna } \\
\text { on the crawler dump } \\
\text { truck is orthogonal. }\end{array}$ & $\begin{array}{l}\text { A short antenna height, } \\
\text { combined with uneven } \\
\text { ground meant that a } \\
\text { sufficient signal } \\
\text { strength could not be } \\
\text { obtained. }\end{array}$ & As at left & As at left \\
\hline
\end{tabular}

\subsection{Examinations}

Based on the above tests, the following results were obtained for the portable robot system under WLAN control.

(1) Performance of the portable robot-controlled backhoe

The performance of the portable robot-controlled backhoe is greater than $60 \%$ that of a manned backhoe, and broadly comparable to that of purpose-built, remote control construction vehicles.

(2) Performance of the portable robot-controlled crawler dump truck

An operator for crawler dump truck claimed that long periods of operation on irregular ground was difficult, as the irregularity produced a lot of vibration at the operator seat. On the basis of this claim, it is reasonable to use the remotely controlled unmanned crawler dump truck to reduce the operators' physical fatigue. As the vibration may also have detrimental effects on the crawler dump truck and the robot system, detailed inspections should be made after operations.

(3) Wireless local area network system

It is recommended that the locations and shapes (wider angles) of antennas of mobile objects and base / relay stations should be able to be easily changed in situ, in order to improve reception efficiency of radio waves where the ground slopes unevenly. Also, it is recommended that the antenna system should be changed from a single antenna system to a double antenna system because the modified system can solve the situation where the vehicle itself blocks radio waves.

\section{Conclusions}

From our tests, we have shown that a backhoe and crawler dump truck can be operated simultaneously by two remotely controlled portable robots at a relatively high level of efficiency.

In the case where a WLAN control system was used, it was shown that problems caused by roaming (e.g. switching control from one base station to another) can be easily solved using existing wireless communication technologies.

The focus of future development of this portable robot system will be to expand its application to hazardous and unpleasant works in general civil engineering projects, in addition to application to disaster prevention works. In order to expand the application areas, it is crucial to incorporate up-to-date visual information technologies, communication technologies and location identification technologies into the current system.

\section{REFERENCES}

[1] Chayama K. and Fujioka A., "Disaster restoration works using unmanned construction vehicles (applications of remotely operated robot)", Journal of JSCE, January, 2003.

[2] Advanced Construction Technology Center, "Guidebook for unmanned construction technology at emergency”, July, 2001. 